\title{
Thiamine additive engineering enables improved film formation towards high efficiency and moisture stability in perovskite solar cells
}

\author{
Peng Zhang, Fengren Cao*, Wei Tian and Liang $\mathrm{Li}^{*}$
}

\begin{abstract}
Perovskite solar cells (PSCs) attract widespread research interest due to their exceptional properties. However, the instability of the perovskite layer, especially the moisture instability, and existing defects seriously restrict the performance and limit the development of PSCs towards commercialization. Herein, we fabricate moisture-stable and efficient PSCs by incorporating a thiamine (THM) additive into a lead iodide $\left(\mathrm{PbI}_{2}\right)$ precursor using a two-step spin-coating method. This strategy enables a better interaction between the THM additive and $\mathrm{PbI}_{2}$. Then, a higher energy barrier is produced when the material reacts with A-site cations to form perovskite crystals, resulting in larger grains and better-quality perovskite films. Through optimization of the concentration of the THM additive, the optimal perovskite achieves improved moisture stability and decreased trap states; thus, the corresponding unencapsulated devices achieve a remarkable power conversion efficiency (PCE) of $21.40 \%$ and maintain $>\mathbf{9 2 \%}$ of their initial PCE after $180 \mathrm{~h}$ in ambient air ( $\sim 50 \%$ humidity). The excellent performance is mainly attributed to the fact that THM promotes crystal growth and passivates defects in perovskite films.
\end{abstract}

Keywords: perovskite, moisture stability, solar cell, passivation

\section{INTRODUCTION}

Metal halide perovskite solar cells (PSCs) are promising candidates for photoelectric conversion devices due to their optoelectronic characteristics. Currently, the highest certified power conversion efficiency (PCE) of devices has reached 25.5\% [1]. However, the instability of the perovskite layer in the ambient environment (light illumination, heat treatment or moisture erosion) [2-5], and the existing defects seriously restrict the performance and limit its development towards practical applications and commercialization [6-10]. Among the various environmental factors that cause instability, moisture instability is a major obstacle because of its severe harmfulness, which causes hydrate formation, promoting the irreversible decomposition of perovskite accompanied by a sharp decline in optical absorption and severe electron-hole recombination $[11,12]$. Moreover, moisture is also the most difficult to control in the actual working environment due to the large humidity range. Thus, it is desirable to explore an appropriate strategy to passivate film defects and improve the moisture stability.

To date, tremendous efforts have been dedicated to improving the moisture stability and reducing intrinsic defects [13-18]. For instance, many different kinds of polymers have been added to perovskite precursor solutions to tune the crystallinity and morphology of perovskite layers [16,19-23]. The polymerization-assisted grain growth strategy can effectively passivate the uncoordinated lead ions when the polymers are anchored on the boundaries after perovskite film formation or make the energy level of the perovskite and transport layer match better $[19,21]$. In addition, some molecules containing cross-linked and hydrophobic functional groups were post-treated on the surface of perovskite to form chemical bonds or hydrogen bonds with perovskite to impede the penetration of water molecules into the perovskite layer and improve the moisture resistance stability of the film [24-28]. These interfacial materials could not only defend against water infiltration but also improve the device performance with excellent charge transfer properties at the same time [24]. However, the addition of polymer materials most likely affects the crystallization of perovskite or hinders the transmission efficiency of the carrier due to their poor conductivity. Interfacial treatment with molecules may form a dense, poorly conductive layer, and commonly used solvents (such as isopropanol (IPA)) will inevitably affect the quality of the underlying perovskite film [22]. Recently, Yang's group $[7,19]$ found that adding a polymer or molecule to the lead iodide $\left(\mathrm{PbI}_{2}\right)$ precursor through a two-step preparation method can enable a more sufficient interaction between the additives and $\mathrm{PbI}_{2}$. The interaction produces a higher energy barrier when the $\mathrm{PbI}_{2}$ crystals react with A-site cations to form perovskite crystals, which helps to form larger grains and better-quality perovskite films. However, the additives currently used to passivate perovskite defects will either redissolve in IPA in the second step or only have a limited variety and number of functional groups so that it is difficult to interact with different types of solvated $\mathrm{Pb}^{2+}$ atoms. Therefore, it is necessary to select more suitable additives for this novel monomer additive strategy.

Herein, we introduce for the first time the small-molecule thiamine (THM), which has a thiazole ring, a pyrimidine carbon ring and an amino group $\left(-\mathrm{NH}_{2}\right)$, into the $\mathrm{PbI}_{2}$ precursor to form a high-quality perovskite film, thereby improving the performance and moisture stability of PSCs. The $\mathrm{C}=\mathrm{N}$ in the thiazole ring and pyrimidine carbon can interact with lead ions, and $-\mathrm{NH}_{2}$ can interact with iodide ions in perovskite [29-35], which will delay the crystallization rate and guide the crystal growth and passivate defects caused by undercoordinated lead

School of Physical Science and Technology, Center for Energy Conversion Materials \& Physics (CECMP), Jiangsu Key Laboratory of Thin Films, Soochow University, Suzhou 215006, China

* Corresponding authors (emails: lli@suda.edu.cn (Li L); frcao@suda.edu.cn (Cao F)) 
and iodide ions. Through optimizing the concentration of the THM additive, a high-quality perovskite film with improved crystallinity, larger grain size, fewer defects, and improved moisture stability (remaining in black phase for $12 \mathrm{~h}$ at a relative humidity of 99\%) was obtained. Finally, the optimal device obtained an enhanced PCE of $21.40 \%$ compared with $19.60 \%$ for the control device, and the corresponding unencapsulated devices retained $>92 \%$ of the initial PCE after $180 \mathrm{~h}$ in air with a humidity of $\sim 50 \%$. These results provide a promising strategy for constructing high-performance perovskite devices with highquality perovskite films and moisture stability.

\section{RESULTS AND DISCUSSION}

The fabrication process of the perovskite devices is presented in Fig. 1a. In brief, a $\mathrm{SnO}_{2}$ thin film was coated on indium tin oxide (ITO) substrates by a spin-coating and annealing process. Then, a $\mathrm{FA}_{0.85} \mathrm{MA}_{0.15} \mathrm{PbI}_{3}\left(\mathrm{FA}=\mathrm{CH}\left(\mathrm{NH}_{2}\right)_{2}, \mathrm{MA}=\mathrm{CH}_{3} \mathrm{NH}_{3}\right)$ film was covered on the $\mathrm{SnO}_{2} /$ ITO substrates by a conventional two-step deposition strategy [25]. In this process, different concentrations $\left(0,0.05,0.1\right.$ and $\left.0.15 \mathrm{mg} \mathrm{mL}^{-1}\right)$ of THM within the $\mathrm{PbI}_{2}$ precursor solution were spin-coated on the $\mathrm{SnO}_{2} / \mathrm{ITO}$ substrate and annealed at an optimized temperature (Fig. S1). The corresponding final perovskite films are labeled as $\mathrm{FA}_{0.85} \mathrm{MA}_{0.15} \mathrm{PbI}_{3}$ $X$, where $X$ represents the concentration of THM. Finally, a spiro-OMTAD layer and 90-nm-thick Ag were deposited on the $\mathrm{FA}_{0.85} \mathrm{MA}_{0.15} \mathrm{PbI}_{3}-X$ film to obtain the final device. The architecture of the device is shown in Fig. 1b, and the detailed preparation process is presented in the experimental section (see Supplementary information).

Fig. 2a displays the molecular structure of THM, and the probable interaction between two neighboring grains with THM is illustrated in Fig. 2 b. The $\mathrm{C}=\mathrm{N}$ probably interacts with lead ions in perovskite, and the ammonium ion interacts with iodide ions. To prove the interaction between THM and $\mathrm{FA}_{0.85} \mathrm{MA}_{0.15}$ $\mathrm{PbI}_{3}$ and determine the exact mechanism of the reaction, Fourier transform infrared (FTIR) spectra of pure THM and THM-PbI hybrid films were measured. As shown in Fig. $2 c$, the $\mathrm{C}=\mathrm{N}$ vibration peak of molecular THM is $1658.74 \mathrm{~cm}^{-1}$ and moves to $1641.38 \mathrm{~cm}^{-1}$ after the reaction with $\mathrm{PbI}_{2}$. This indicates a strong interaction between $\mathrm{THM}$ and $\mathrm{PbI}_{2}$, and the reaction sites are between the $\mathrm{C}=\mathrm{N}$ and uncoordinated $\mathrm{Pb}^{2+}$. To further confirm the conclusion drawn from the FTIR results, X-ray photoelectron spectroscopy (XPS) and X-ray diffraction (XRD) measurements were adopted as the supplementary information. For the pure perovskite film (Fig. 2d), the peaks at 143.28 and $138.38 \mathrm{eV}$ are indexed to $\mathrm{Pb}^{2+}$ [36-39]. The two weak satellite peaks at 136.68 and $141.58 \mathrm{eV}$ are assigned to metallic $\mathrm{Pb}\left(\mathrm{Pb}^{0}\right)$, which is caused by unsaturated lead. After introducing the THM additive, the peaks of $\mathrm{Pb}^{2+}$ shift to lower binding energy, and the two peaks of $\mathrm{Pb}^{0}$ disappear compared with the pristine perovskite film, indicating increased electron density on the $\mathrm{Pb}$ nucleus and decreased defect density due to coordination of THM with undercoordinated $\mathrm{Pb}^{2+}$ ions. Correspondingly, the peaks of I $3 \mathrm{~d}$ in the perovskite film with THM additive shifted to higher binding energies (Fig. 2e), which should be attributed to the strong electronic interactions produced by the hydrogen bond between the $-\mathrm{NH}_{2}$ of THM and $\mathrm{I}^{-}$in the perovskite film. These results further confirmed the passivation effect of THM on the perovskite film. Fig. $2 \mathrm{f}$, g show the XRD patterns of the $\mathrm{PbI}_{2}$ and $\mathrm{PbI}_{2}$-THM hybrid films before and after annealing treatments. The peak at $9.8^{\circ}$ of the unannealed films corresponds to the $\mathrm{PbI}_{2}$-dimethyl sulfoxide (DMSO) intermediate phase. After annealing, the pristine $\mathrm{PbI}_{2}$ film has a strong lead iodide crystal phase, while the emergence of crystallinity is suppressed by the hybrid film [40]. This indicates that the sufficient interaction between the $\mathrm{THM}$ and $\mathrm{PbI}_{2}$ and $\mathrm{Pb}^{2+}$ probably locked in the crystal lattice. Moreover, the corresponding XRD patterns of $\mathrm{FA}_{0.85} \mathrm{MA}_{0.15} \mathrm{PbI}_{3}-X$ illustrate that the intensity ratio between the $\mathrm{PbI}_{2}$ peak at $12.8^{\circ}$ and the (100) peak of perovskite at $14.0^{\circ}$ decreases from 1.9 to 1.2 as the THM doping concentration increases from 0 to $0.15 \mathrm{mg} \mathrm{mL}^{-1}$ (Fig. $2 \mathrm{~h}$ ), indicating that the excess lead iodide can be neutralized after the formation of THM-treated perovskite.

Top-view scanning electron microscopy (SEM) images of the pure $\mathrm{FA}_{0.85} \mathrm{MA}_{0.15} \mathrm{PbI}_{3}$ and $\mathrm{FA}_{0.85} \mathrm{MA}_{0.15} \mathrm{PbI}_{3}-X$ films are presented in Fig. 3a, b and Fig. S2. The grain size gradually increases from 1400 to $1700 \mathrm{~nm}$ as the doping concentration increases from 0 to $0.1 \mathrm{mg} \mathrm{mL}^{-1}$, while the grain size begins to decrease when the doping concentration further reaches $0.15 \mathrm{mg} \mathrm{mL}^{-1}$. This trend is attributed to the presence of a strong interaction between $\mathrm{PbI}_{2}$ and $\mathrm{THM}$, which leads to a higher activation energy and then reduces the reaction rate of the $\mathrm{PbI}_{2}$ and
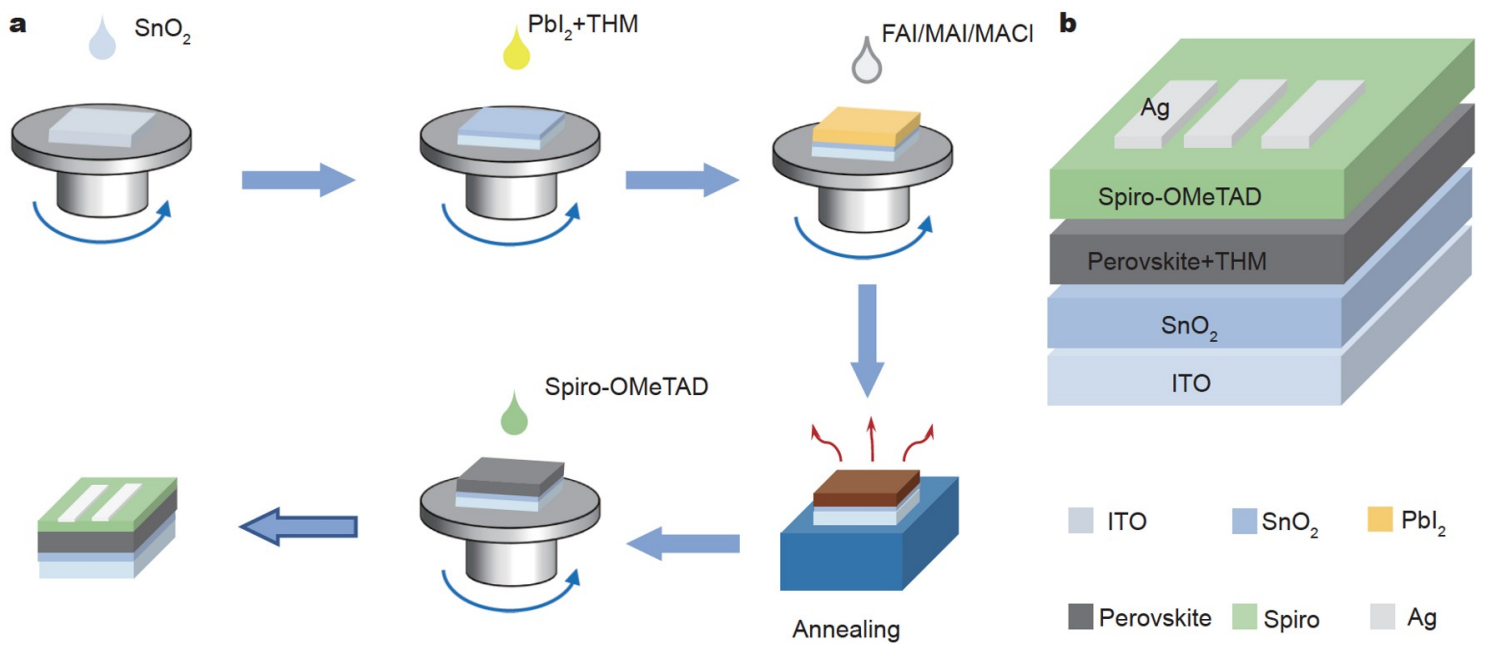

Figure 1 (a) Schematic of the fabrication process of the perovskite devices. (b) Schematic architecture of the final device. 
a

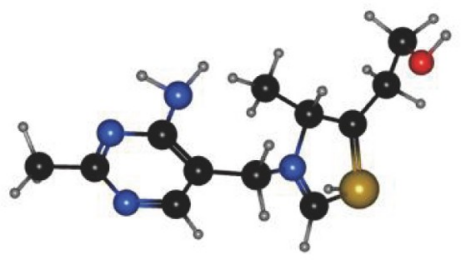

Thiamine (THM)
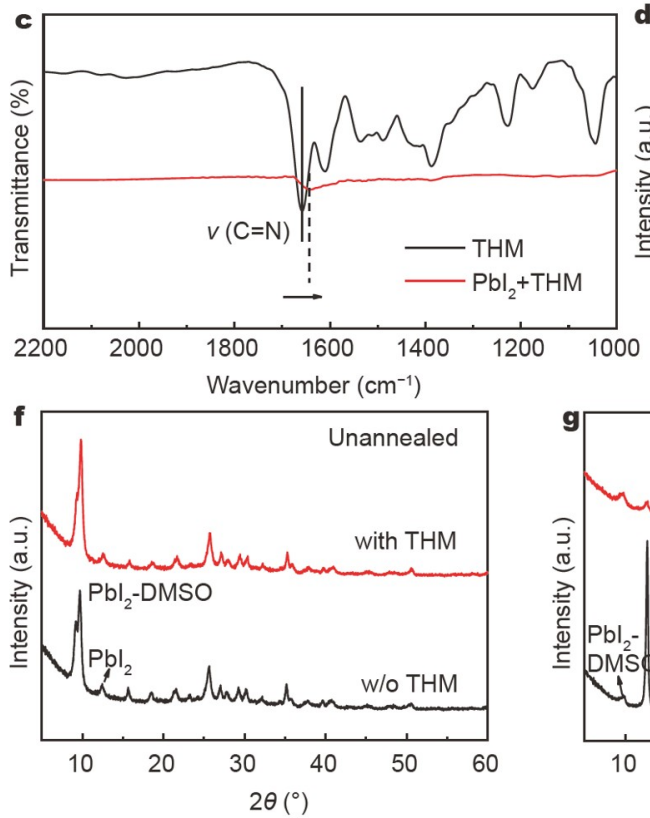

b

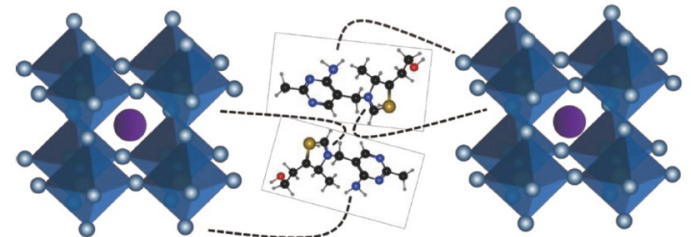

$\begin{array}{cccccccc}- & 0 & 0 & 0 & 0 & 0 & 0 & 0 \\ \text { MA/FA } & \text { Pb } & \text { I } & \text { C } & \text { N } & \text { O } & \text { S } & \text { H }\end{array}$
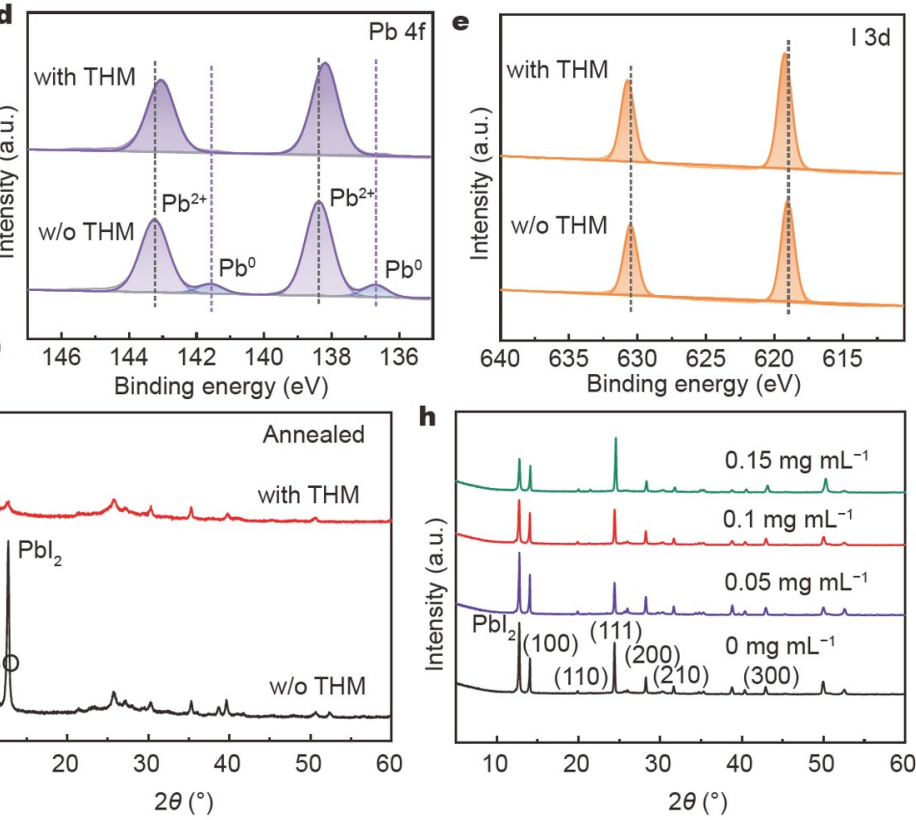

Figure 2 (a) Molecular structure of THM. (b) Schematic illustration of the interaction between two neighboring grains and THM. (c) FTIR spectra of pure THM and $\mathrm{PbI}_{2} / \mathrm{THM}$ hybrid film. XPS spectra of FAMAPbI ${ }_{3}$ and $\mathrm{FAMAPbI}_{3}-0.1$ : (d) $\mathrm{Pb} 4 \mathrm{f}$ and (e) I $3 \mathrm{~d}$ orbitals. XRD patterns of the pure $\mathrm{PbI}_{2}$ film and $\mathrm{PbI}_{2}-$ THM film: (f) before and (g) after annealing. (h) XRD of perovskite films with different concentrations of THM.

a
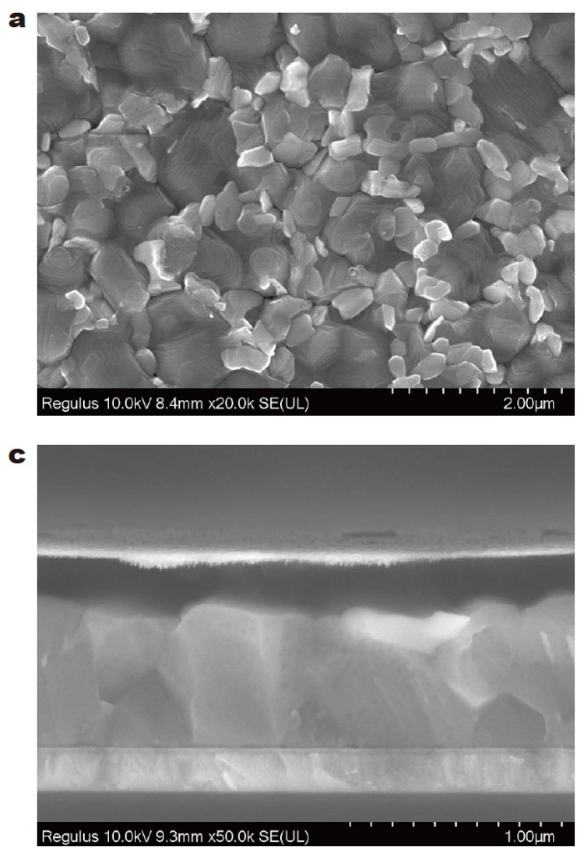

b
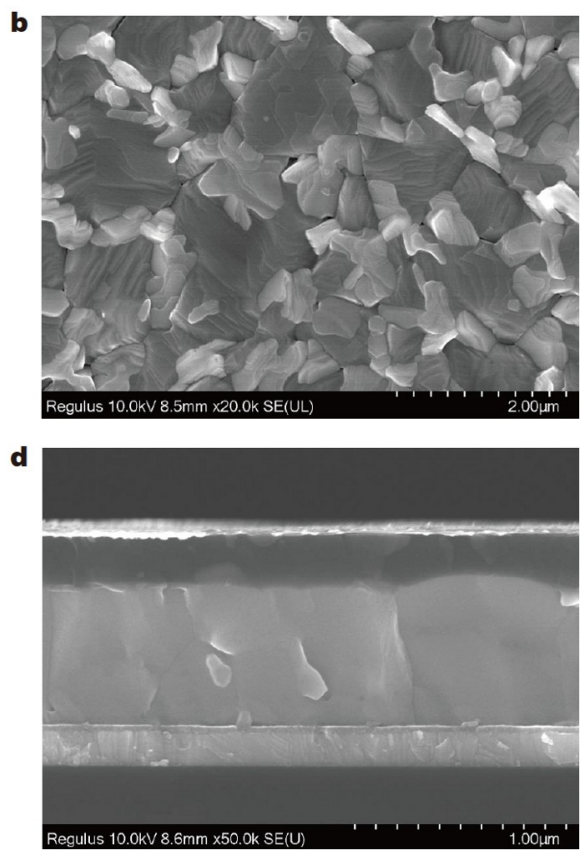

Figure 3 Top-view SEM images of perovskite films with (a) 0 and (b) $0.1 \mathrm{mg} \mathrm{mL}^{-1}$ THM additives, (c, d) cross-sectional SEM images of the corresponding perovskite devices. 
$\mathrm{FAI} / \mathrm{MAI} / \mathrm{MACl}$ solutions in the second step of the two-step preparation process [19]. However, when the doping concentration is further increased, more nucleation rapidly occurs at the unformed complex as the interaction force between THM and $\mathrm{PbI}_{2}$ increases. The corresponding cross-sectional SEM images (Fig. 3c, d) demonstrate that the introduction of THM helps to improve the surface flatness of the $\mathrm{FA}_{0.85} \mathrm{MA}_{0.15} \mathrm{PbI}_{3}$ film. In addition, the steady-state photoluminescence (PL) spectra and the corresponding time-resolved PL (TRPL) decay with a structure of $\mathrm{ITO} / \mathrm{SnO}_{2} /$ perovskite were measured to clarify the beneficial effect of the THM additive on defect passivation (Fig. 4). Fig. 4a displays the PL spectra of the perovskite films with different THM concentrations, and the intensities of $\mathrm{FA}_{0.85} \mathrm{MA}_{0.15} \mathrm{PbI}_{3}, \quad \mathrm{FA}_{0.85} \mathrm{MA}_{0.15} \mathrm{PbI}_{3}-0.05, \quad \mathrm{FA}_{0.85} \mathrm{MA}_{0.15} \mathrm{PbI}_{3}-0.1$, and $\mathrm{FA}_{0.85} \mathrm{MA}_{0.15} \mathrm{PbI}_{3}-0.15$ are $6.72 \times 10^{5}, 4.14 \times 10^{5}, 3.39 \times 10^{5}$ and $4.84 \times 10^{5}$ (a.u.), respectively. The weaker strength of the PL intensity indicates the more efficient charge extraction efficiency of the interface between the perovskite and electron transport layer, which can be interpreted as the quenching of more carriers due to interface transmission rather than radiative recombination. Moreover, the blueshift of the peak for the THM-treated perovskite film further indicates a reduction in defect states compared with the pristine film [8]. The corresponding TRPL decay is presented in Fig. $4 \mathrm{~b}$, and the fitting parameters are summarized in Table S1. The smallest PL decay (179.19 ns) suggests a more efficient electron extraction process between $\mathrm{FA}_{0.85} \mathrm{MA}_{0.15} \mathrm{PbI}_{3}-0.1$ and $\mathrm{SnO}_{2}$. In addition, the PL and TRPL spectra with a structure of glass/perovskite are provided in Fig. S3 and the fitting parameters are summarized in Table S2. The results show that the perovskite film treated with THM has more carriers and longer life than the control film, indicating that the THM-treated perovskite film has better quality. The results are consistent with the conclusion obtained from the perovskite film on $\mathrm{SnO}_{2}$ /ITO substrate. Moreover, we utilized the space-charge-limited-current (SCLC) technique to quantitatively study the defect density in the $\mathrm{FA}_{0.85} \mathrm{MA}_{0.15} \mathrm{PbI}_{3}-X$ films. The associated current-voltage curves for both pristine and THM-treated perovskite films are displayed in Fig. 4c. The trap filled limit voltage $\left(V_{\text {TFL }}\right)$ is $0.76 \mathrm{~V}$ for the $\mathrm{FA}_{0.85} \mathrm{MA}_{0.15} \mathrm{PbI}_{3}$-based device and $0.51 \mathrm{~V}$ for the $\mathrm{FA}_{0.85} \mathrm{MA}_{0.15} \mathrm{PbI}_{3}-0.1$-based device. The defect density $\left(N_{\text {defects }}\right)$ is calculated from the equation $N_{\text {defects }}=$ $2 \varepsilon \varepsilon_{0} V_{\mathrm{TFL}} / e L^{2}$, where $\varepsilon$ and $L$ are the dielectric constant and thickness of the perovskite, respectively; $\varepsilon_{0}, V_{\mathrm{TFL}}$, and $e$ are the vacuum permittivity, trap filled limit voltage, and electron charge, respectively. A lower defect state density was obtained by the optimized device $\left(2.09 \times 10^{16} \mathrm{~cm}^{-1}\right)$ compared with the
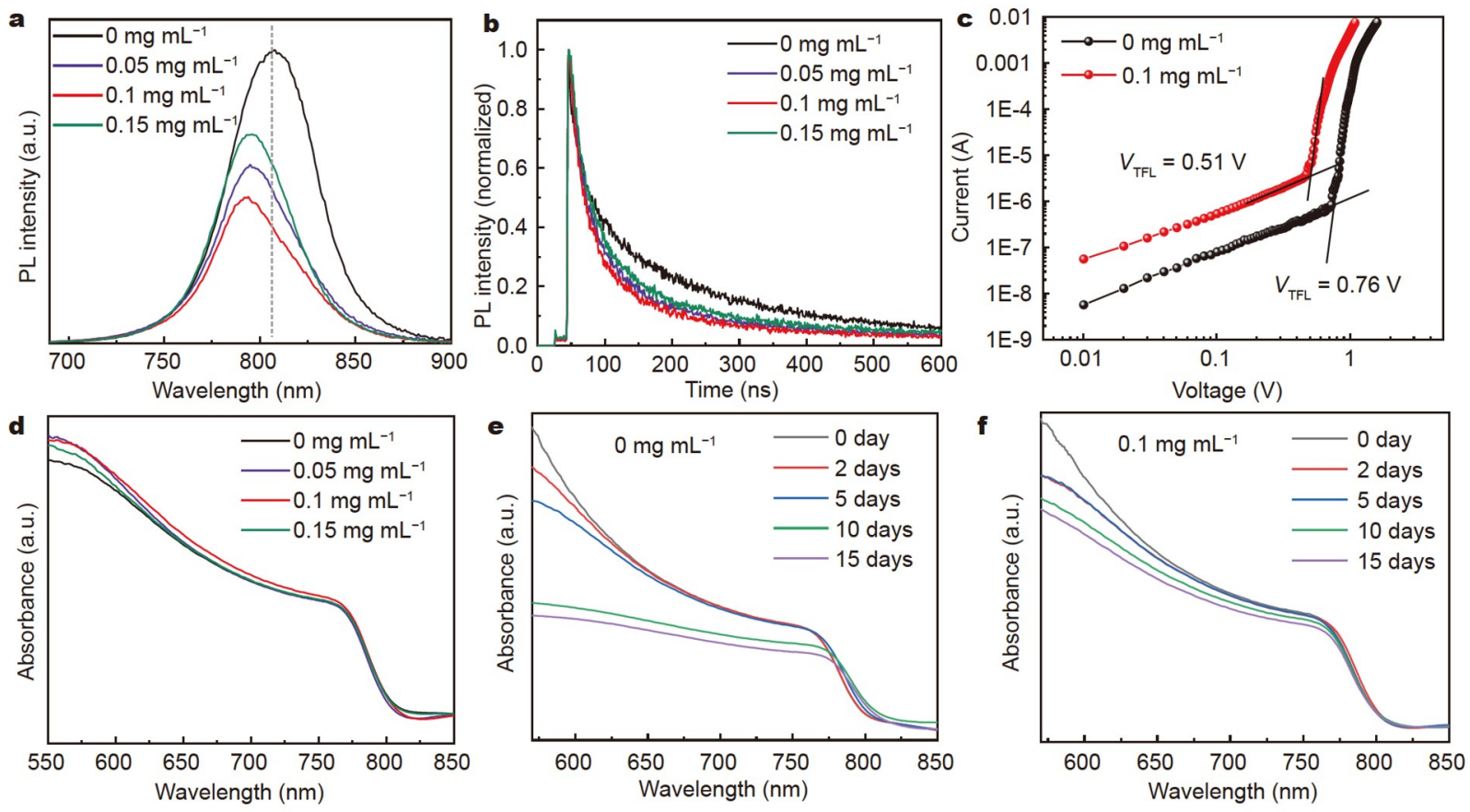

$\mathbf{g}$

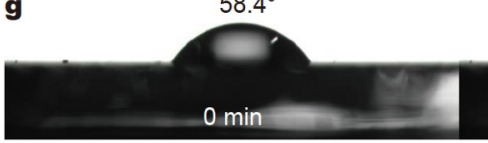

$51.6^{\circ}$

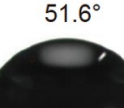

$5 \mathrm{~min}$

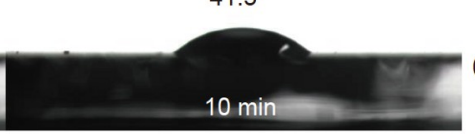

$0 \mathrm{mg} \mathrm{mL}^{-1}$

h

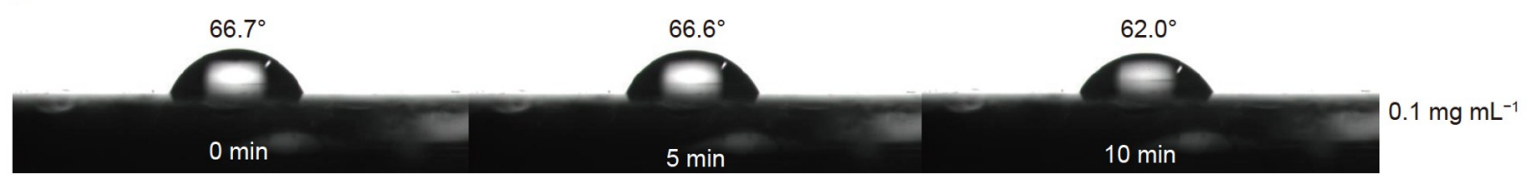

Figure 4 (a) PL and (b) TRPL spectra of perovskite films treated with different concentrations of THM. (c) SCLC measurements of electron-only devices based on $\mathrm{FAMAPbI}_{3}$ and $\mathrm{FAMAPbI}_{3}-0.1$ films. (d) UV-visible absorption spectra of perovskite films with different THM concentrations. Absorption spectra of (e) pristine and (f) THM-treated perovskite films exposed to ambient air with an RH of $\sim 50 \%$ for different days. WCA with time based on (g) pristine and (h) THM-treated perovskite films. 
pristine perovskite film $\left(3.12 \times 10^{16} \mathrm{~cm}^{-1}\right)$, and the result is consistent with the PL and TRPL results. In addition, the initial ultraviolet (UV) absorption spectra of the $\mathrm{FA}_{0.85}-\mathrm{MA}_{0.15} \mathrm{PbI}_{3}-\mathrm{X}$ film are presented in Fig. $4 \mathrm{~d}$. All perovskite films have an identical absorption edge of $805 \mathrm{~nm}$ and the same absorption intensity, indicating that the THM additive has negligible effects on the $\mathrm{FA}_{0.85} \mathrm{MA}_{0.15} \mathrm{PbI}_{3}$ phase and light utilization capacity. However, the absorption of the control film declines gradually from 0 to 5 days and exhibits a sharp drop for ten days during storage under ambient conditions with a humidity of $\sim 50 \%$, while the film with THM treatment only exhibits a slight decrease during storage for 15 days (Fig. 4e, f). Moreover, the water resistance is also important for perovskite films and greatly improved with the THM additive. As seen in the water contact angle (WCA) characterization in Fig. 4g, h, with addition of THM, the WCA of the perovskite film becomes larger, indicating enhanced hydrophobicity of the hybrid film. Meanwhile, the WCA of the control film decreases sharply from $58.4^{\circ}$ to $41.3^{\circ}$ after $10 \mathrm{~min}$, while the optimized film with THM only has a very small variation from $66.7^{\circ}$ to $62.0^{\circ}$. This result indicates that the addition of THM to perovskite films can prevent further reaction between the surface of the film and water, which should be attributed to the formation of a dense film due to the interaction of THM molecules and perovskite. Furthermore, to test the limit of the moisture resistance of the $\mathrm{FA}_{0.85} \mathrm{MA}_{0.15} \mathrm{PbI}_{3}-X$ film, the control film and THM-treated film were placed in an airtight and low-pressure container with humidity of $99 \%$. The
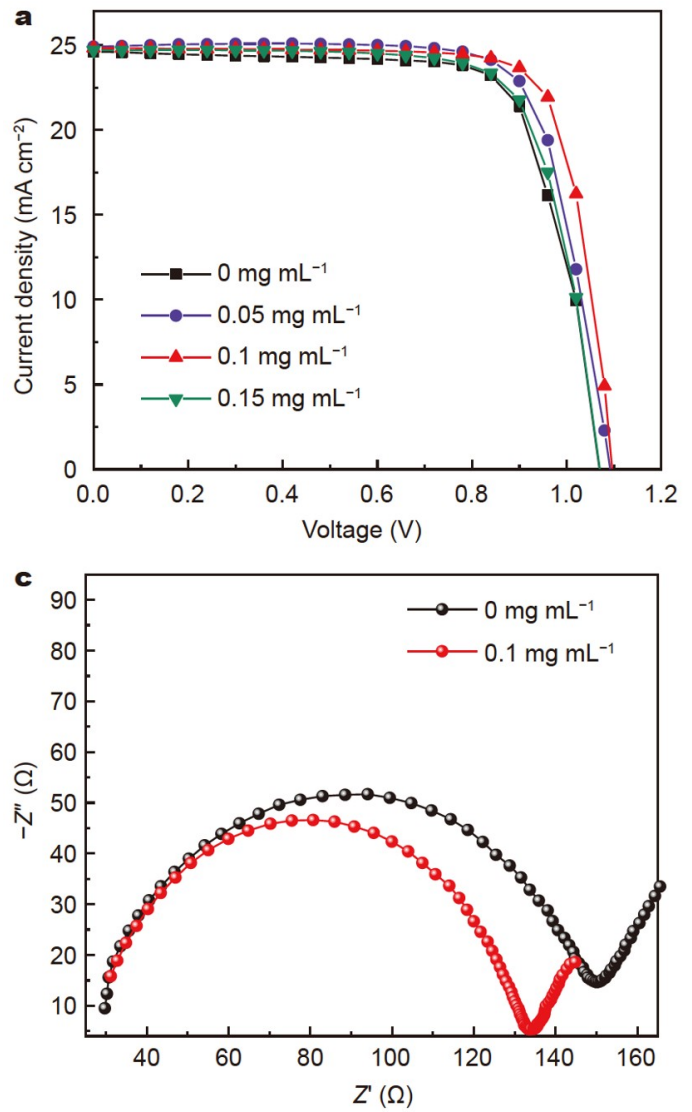

pristine perovskite film decomposes into large amounts of lead iodide after $6 \mathrm{~h}$ and almost completely decomposes after $12 \mathrm{~h}$, while the THM-treated film $\left(1 \mathrm{mg} \mathrm{mL}^{-1}\right)$ remains unchanged within $9 \mathrm{~h}$ and only decomposes slightly after $12 \mathrm{~h}$ (Fig. S4). These results indicate that moisture stability is greatly enhanced with the THM additive integrated with the perovskite film.

Fig. 5a displays the current density-voltage $(J-V)$ characteristics of $\mathrm{FA}_{0.85} \mathrm{MA}_{0.15} \mathrm{PbI}_{3}-\mathrm{X}$-based devices. The detailed photovoltaic parameters are summarized in Table 1 . In addition, the corresponding statistical distributions are summarized in Fig. S5. The devices based on the $\mathrm{FA}_{0.85} \mathrm{MA}_{0.15} \mathrm{PbI}_{3}$ film with a suitable THM additive exhibit enhanced PCE, open-circuit voltage $\left(V_{\text {oc }}\right)$, short-circuit current density $\left(J_{\mathrm{sc}}\right)$, and fill factor $(\mathrm{FF})$ compared with the control device, and the $\mathrm{FA}_{0.85} \mathrm{MA}_{0.15} \mathrm{PbI}_{3}-0.1$-based device delivers the highest PCE of $21.40 \%$ with an enhanced $V_{o c}$ of $1.10 \mathrm{~V}, J_{\mathrm{sc}}$ of $24.83 \mathrm{~mA} \mathrm{~cm}^{-2}$, and $\mathrm{FF}$ of $78.64 \%$.

The integrated current of the external quantum efficiency (EQE) (Fig. S6) is $23.6 \mathrm{~mA} \mathrm{~cm}^{-2}$. The slight reduction is caused by the different effects of the factors, such as surface defect states, light intensity and frequency. Note that although a slightly large concentration of THM cannot improve the efficiency of the device, it does not cause substantial damage either (Fig. S7). The improvement of $V_{\mathrm{oc}}$ and $\mathrm{FF}$ is due to the better quality of the perovskite film and good defect passivation impact with the introduction of THM. Repeatability and hysteresis are also critical parameters of PSCs; thus, Fig. 5b summarizes the efficiency distribution of thirty devices, and Fig. S8 compares the $J-V$
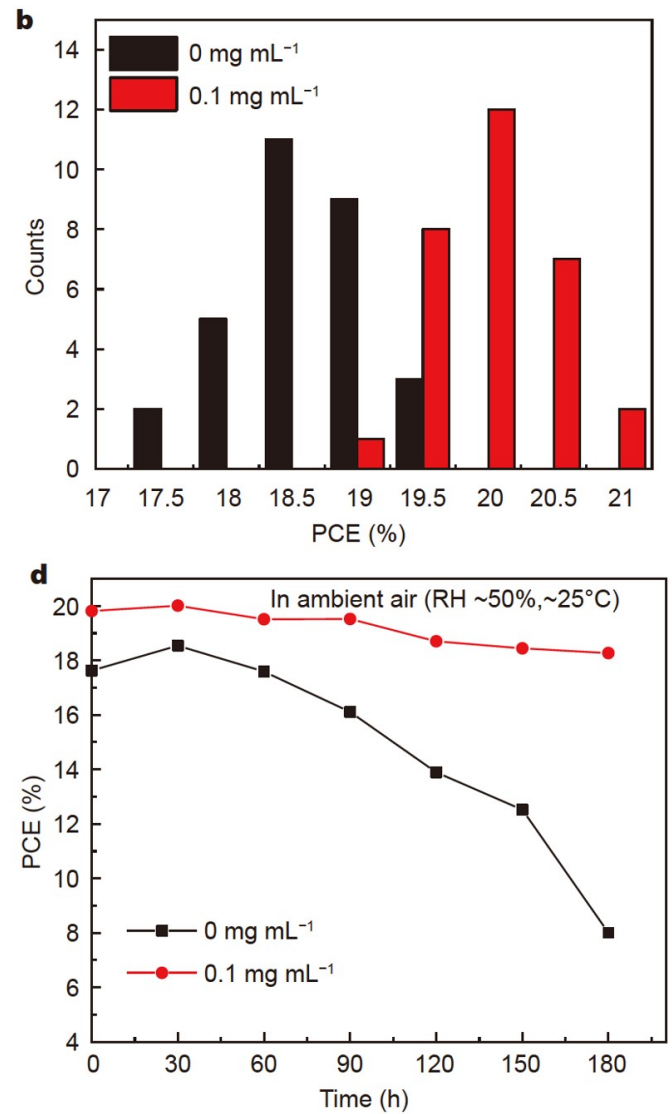

Figure 5 (a) $J$ - $V$ curves of the hybrid PSCs with different concentrations of THM additive. (b) Histogram of the efficiency distribution of 30 devices based on the pristine and THM-treated perovskites. (c) Nyquist plot of PSCs based on the control and optimized hybrid perovskite devices. (d) The air stability of $\mathrm{FAMAPbI}_{3}$ - and $\mathrm{FAMAPbI}_{3}-0.1$-based devices. 
Table 1 Summary of the photovoltaic parameters of PSCs with different concentrations of THM additive

\begin{tabular}{ccccc}
\hline $\begin{array}{c}\text { Concentration } \\
\left(\mathrm{mg} \mathrm{mL}^{-1}\right)\end{array}$ & $V_{\mathrm{oc}}(\mathrm{V})$ & $J_{\mathrm{sc}}\left(\mathrm{mA} \mathrm{cm}^{-2}\right)$ & FF (\%) & PCE (\%) \\
\hline 0 & 1.07 & 24.62 & 74.43 & 19.60 \\
0.05 & 1.09 & 24.92 & 75.94 & 20.66 \\
0.1 & 1.10 & 24.83 & 78.64 & 21.40 \\
0.15 & 1.07 & 24.70 & 74.98 & 19.82 \\
\hline
\end{tabular}

curves under reverse and forward scan directions of the $\mathrm{FA}_{0.85^{-}}$ $\mathrm{MA}_{0.15} \mathrm{PbI}_{3}$ and optimal $\mathrm{FA}_{0.85} \mathrm{MA}_{0.15} \mathrm{PbI}_{3}-0.1$-based devices. Good normal distribution and improved median efficiency prove the good repeatability of the $\mathrm{FA}_{0.85} \mathrm{MA}_{0.15} \mathrm{PbI}_{3}-0.1$-based device. The notable reduction in the hysteresis benefits from the synergetic effect of the grain size increase and defect passivation after doping with THM. In addition, electrochemical impedance spectroscopy (EIS) measurements are used as a supplement to the investigation of charge transport. As shown in Fig. $5 \mathrm{c}$, the related equivalent circuit model for EIS fitting includes the device series resistance $\left(R_{\mathrm{s}}\right)$, charge transport resistance $\left(R_{\mathrm{ct}}\right)$, and recombination resistance $\left(R_{\mathrm{rec}}\right)$. The $R_{\mathrm{ct}}$ is systematically reduced from $110 \Omega$ of the control device to $95.8 \Omega$ of the optimized device. A lower $R_{\mathrm{ct}}$ indicates a higher charge transport capability, and this result further confirms the better film morphology and defect passivation produced by THM treatment. For confirmation, we adopt long-term stability tests for unencapsulated devices under ambient conditions with humidity of $\sim 50 \%$ and a temperature of $\sim 25^{\circ} \mathrm{C}$ (Fig. $5 \mathrm{~d}$ ). After $180 \mathrm{~h}$ of exposure to air, the device with THM additive retains $>92 \%$ of its initial PCE, while the pure perovskite-based device drops rapidly to $45 \%$ of its initial PCE during the same aging time. The results obtained with the final devices are consistent with the results obtained during the film research process and further indicate that proper THM addition can improve the film morphology and passivate defects in the perovskite film, thereby improving the performance of the corresponding device.

\section{CONCLUSIONS}

In summary, we have successfully improved the quality of the $\mathrm{FA}_{0.85} \mathrm{MA}_{0.15} \mathrm{PbI}_{3}$ film by introducing a THM molecule additive. After the introduction of THM, the defects at the perovskite grain boundaries are passivated, the perovskite film becomes flattened, and the hydrophobicity of the perovskite film is improved. Hence, the best performing device with the optimal THM additive attained an efficiency of $21.40 \%$ and improved stability. These results suggest that integrating cross-linked materials with perovskites by a novel additive use strategy is a promising strategy for fabricating high-performance perovskite devices with high-quality stable perovskite films.

Received 25 May 2021; accepted 28 July 2021;

published online 6 September 2021

1 National Renewable Energy Laboratory. Best Research-Cell Effciencies Chart, https://www.nrel.gov/pv/cell-efficiency.html

2 Dong $\mathrm{Q}, \mathrm{Zhu} \mathrm{C}$, Chen $\mathrm{M}$, et al. Interpenetrating interfaces for efficient perovskite solar cells with high operational stability and mechanical robustness. Nat Commun, 2021, 12: 973

3 Wang R, Mujahid M, Duan Y, et al. A review of perovskites solar cell stability. Adv Funct Mater, 2019, 29: 1808843

4 Li N, Niu X, Chen Q, et al. Towards commercialization: The operational stability of perovskite solar cells. Chem Soc Rev, 2020, 49: 82358286

5 Zhang S, Liu Z, Zhang W, et al. Barrier designs in perovskite solar cells for long-term stability. Adv Energy Mater, 2020, 10: 2001610

6 Gao F, Zhao Y, Zhang X, et al. Recent progresses on defect passivation toward efficient perovskite solar cells. Adv Energy Mater, 2019, 10: 1902650

7 Zhao Y, Zhu P, Huang S, et al. Molecular interaction regulates the performance and longevity of defect passivation for metal halide perovskite solar cells. J Am Chem Soc, 2020, 142: 20071-20079

8 Mai CL, Zhou Q, Xiong Q, et al. Donor- $\pi$-acceptor type porphyrin derivatives assisted defect passivation for efficient hybrid perovskite solar cells. Adv Funct Mater, 2021, 31: 2007762

9 Wang R, Xue J, Wang KL, et al. Constructive molecular configurations for surface-defect passivation of perovskite photovoltaics. Science, 2019, 366: $1509-1513$

10 Liu Z, Cao F, Wang M, et al. Observing defect passivation of the grain boundary with 2-aminoterephthalic acid for efficient and stable perovskite solar cells. Angew Chem Int Ed, 2020, 59: 4161-4167

11 Christians JA, Miranda Herrera PA, Kamat PV. Transformation of the excited state and photovoltaic efficiency of $\mathrm{CH}_{3} \mathrm{NH}_{3} \mathrm{PbI}_{3}$ perovskite upon controlled exposure to humidified air. J Am Chem Soc, 2015, 137: 1530-1538

12 Mohamad Noh MF, Arzaee NA, Nawas Mumthas IN, et al. Highhumidity processed perovskite solar cells. J Mater Chem A, 2020, 8: 10481-10518

13 Hui W, Chao L, Lu H, et al. Stabilizing black-phase formamidinium perovskite formation at room temperature and high humidity. Science, 2021, 371: 1359-1364

14 Jeong M, Choi IW, Go EM, et al. Stable perovskite solar cells with efficiency exceeding $24.8 \%$ and $0.3-\mathrm{V}$ voltage loss. Science, 2020, 369: $1615-1620$

15 Zhang F, Xiao C, Chen X, et al. Self-seeding growth for perovskite solar cells with enhanced stability. Joule, 2019, 3: 1452-1463

16 Kim B, Kim M, Lee JH, et al. Enhanced moisture stability by butyldimethylsulfonium cation in perovskite solar cells. Adv Sci, 2020, 7: 1901840

17 Ahmad S, Fu P, Yu S, et al. Dion-Jacobson phase 2D layered perovskites for solar cells with ultrahigh stability. Joule, 2019, 3: 794-806

18 Wang S, Chen H, Zhang J, et al. Targeted therapy for interfacial engineering toward stable and efficient perovskite solar cells. Adv Mater, 2019, 31: 1903691

19 Zhao Y, Zhu P, Wang M, et al. A polymerization-assisted grain growth strategy for efficient and stable perovskite solar cells. Adv Mater, 2020, 32: 1907769

20 Han TH, Lee JW, Choi C, et al. Perovskite-polymer composite crosslinker approach for highly-stable and efficient perovskite solar cells. Nat Commun, 2019, 10: 520

21 Jiang J, Wang Q, Jin Z, et al. Polymer doping for high-efficiency perovskite solar cells with improved moisture stability. Adv Energy Mater, 2018, 8: 1701757

22 Kim M, Motti SG, Sorrentino R, et al. Enhanced solar cell stability by hygroscopic polymer passivation of metal halide perovskite thin film. Energy Environ Sci, 2018, 11: 2609-2619

23 Li X, Zhang W, Wang YC, et al. In-situ cross-linking strategy for efficient and operationally stable methylammoniun lead iodide solar cells. Nat Commun, 2018, 9: 3806

24 Akman E, Akin S. Poly( $N, N^{\prime}$-bis-4-butylphenyl- $N, N^{\prime}$-bisphenyl)benzidine-based interfacial passivation strategy promoting efficiency and operational stability of perovskite solar cells in regular architecture. Adv Mater, 2021, 33: 2006087

25 Guo P, Ye Q, Liu C, et al. Double barriers for moisture degradation: Assembly of hydrolysable hydrophobic molecules for stable perovskite solar cells with high open-circuit voltage. Adv Funct Mater, 2020, 30: 2002639

26 Jiang Q, Zhao Y, Zhang X, et al. Surface passivation of perovskite film 
for efficient solar cells. Nat Photonics, 2019, 13: 460-466

27 Chen J, Park NG. Materials and methods for interface engineering toward stable and efficient perovskite solar cells. ACS Energy Lett, 2020, 5: $2742-2786$

28 Chen H, Liu T, Zhou P, et al. Efficient bifacial passivation with crosslinked thioctic acid for high-performance methylammonium lead iodide perovskite solar cells. Adv Mater, 2020, 32: 1905661

29 Cai Y, Cui J, Chen M, et al. Multifunctional enhancement for highly stable and efficient perovskite solar cells. Adv Funct Mater, 2020, 31: 2005776

30 Chen $\mathrm{H}$, Wei Q, Saidaminov MI, et al. Efficient and stable inverted perovskite solar cells incorporating secondary amines. Adv Mater, 2019, 31: 1903559

31 Yao Q, Xue Q, Li Z, et al. Graded 2D/3D perovskite heterostructure for efficient and operationally stable MA-free perovskite solar cells. Adv Mater, 2020, 32: 2000571

32 Yoo JJ, Wieghold S, Sponseller MC, et al. An interface stabilized perovskite solar cell with high stabilized efficiency and low voltage loss. Energy Environ Sci, 2019, 12: 2192-2199

$33 \mathrm{Wu} \mathrm{X}$, Jiang Y, Chen C, et al. Stable triple cation perovskite precursor for highly efficient perovskite solar cells enabled by interaction with 18C6 stabilizer. Adv Funct Mater, 2019, 30: 1908613

34 Yang S, Chen S, Mosconi E, et al. Stabilizing halide perovskite surfaces for solar cell operation with wide-bandgap lead oxysalts. Science, 2019, 365: 473-478

35 Xue J, Wang R, Chen X, et al. Reconfiguring the band-edge states of photovoltaic perovskites by conjugated organic cations. Science, 2021, 371: 636-640

$36 \mathrm{Wu}$ T, Wang Y, Li X, et al. Efficient defect passivation for perovskite solar cells by controlling the electron density distribution of donor- $\pi$ acceptor molecules. Adv Energy Mater, 2019, 9: 1803766

37 Wu Z, Jiang M, Liu Z, et al. Highly efficient perovskite solar cells enabled by multiple ligand passivation. Adv Energy Mater, 2020, 10: 1903696

38 Gao XX, Luo W, Zhang Y, et al. Stable and high-efficiency methylammonium-free perovskite solar cells. Adv Mater, 2020, 32: 1905502

39 Song S, Park EY, Ma BS, et al. Selective defect passivation and topographical control of 4-dimethylaminopyridine at grain boundary for efficient and stable planar perovskite solar cells. Adv Energy Mater, 2021, 11: 2003382

40 Bai S, Da P, Li C, et al. Planar perovskite solar cells with long-term stability using ionic liquid additives. Nature, 2019, 571: 245-250

Acknowledgements This work was financially supported by the National Natural Science Foundation of China (52025028, 52072254, and 52002258), the Natural Science Foundation of Jiangsu Province (BK20200877), the "Shuangchuang" Program of Jiangsu Province, and the Priority Academic Program Development (PAPD) of Jiangsu Higher Education Institutions.

Author contributions Zhang P and Cao F conducted the experiment and wrote the paper. Cao F and Li L designed this study and analyzed the data. Tian $\mathrm{W}$ offered some helpful suggestions. All authors contributed to the general discussion.

Conflict of interest The authors declare that they have no conflict of interest.

Supplementary information Experimental details and supporting data are available in the online version of the paper.

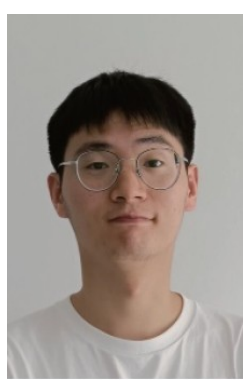

Peng Zhang received his BS at Nanjing Tech University in 2019 . He is currently a master degree candidate in Prof. Liang Li's research group. His research focuses on the field of perovskite solar cells.

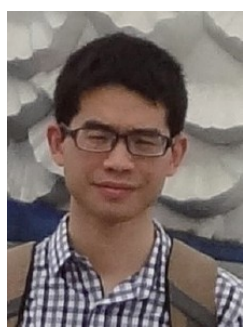

Fengren Cao received his BS and PhD degrees from Soochow University in 2014 and 2019, respectively. Since 2019, he has been an assistant researcher at the School of Physical Science and Technology, Soochow University, China. His research interests focus on the field of optoelectronic conversion materials, especially with a focus on nanostructure-based perovskite devices.

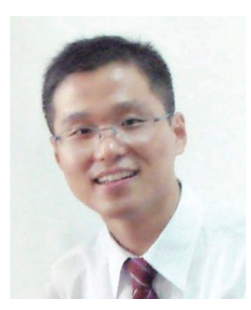

Liang $\mathbf{L i}$ received his $\mathrm{PhD}$ degree from the Institute of Solid State Physics, Chinese Academy of Sciences, in 2006. From 2007 to 2012, he worked at the National University of Singapore (NUS), Singapore; the National Institute of Advanced Industrial Science and Technology (AIST), Japan; the National Institute of Materials Science (NIMS), Japan; and the University of Western Ontario (UWO), Canada. Since August 2012, he has been a full professor at Soochow University, China. His research group focuses on energy and electrochemical batteries. conversion materials for solar cells, photodetectors,

\section{盐酸硫胺添加剂改善钻钛矿的成膜质量以制备高效 的、湿度稳定的钙铁矿太阳能电池}

\author{
张鹏, 曹风人*, 田维, 李亮*
}

摘要 钙钛矿太阳能电池由于其特殊的性质引起了广泛关注. 然而, 钲 钛矿层的不稳定性, 尤其是水分不稳定性以及存在的缺陷, 严重制约了 钲钛矿电池的性能并限制了其商业化发展. 在此, 我们将盐酸硫铵 $(\mathrm{THM})$ 添加剂掺入碘化铅 $\left(\mathrm{PbI}_{2}\right)$ 前驱体中, 使用两步旋涂方法制备出了 耐湿且高效的钙铁矿电池. 这一策略可以使 THM添加剂和 $\mathrm{PbI}_{2}$ 之间产 生更好的相互作用, 当与 $\mathrm{A}$ 位阳离子反应形成钙钛矿晶体时会产生能 量势垒, 从而形成更大的晶粒和质量更好的钙钛矿薄膜. 通过优化 THM添加剂的浓度, 最佳的钲钛矿薄膜实现了湿度稳定性的提高以及 陷阱态密度的降低. 因此, 相应的未封装器件实现了 $21.40 \%$ 的能量转换 效率，并在 $50 \%$ 湿度的空气环境中 180 小时后依旧保持其初始效率的 $92 \%$ 以上. 其优异性能主要归因于THM促进了晶体生长并钝化了钙钛 矿薄膜中的缺陷. 